\title{
Block-Based Development of a Mobile Application in Basic Electrical Concept for Diploma in Electrical Engineering Student
}

\author{
Marriatyi Morsin ${ }^{1 *}$, Halizah Ali ${ }^{1}$ \\ ${ }^{1}$ Department of Electrical Engineering, \\ Politeknik Mersing, Jalan Nitar, 86800 Mersing, Johor, MALAYSIA
}

DOI: https://doi.org/10.30880/jeva.2021.02.02.007

Received 12 August 2021; Accepted 10 October 2021; Available online 30 December 2021

\begin{abstract}
Electrical Technology is one of the main courses for Diploma in Electrical Engineering students in Politeknik Malaysia. The subject has been delivered conventionally; however, due to the Covid-19 pandemic, relatively it has changed the landscape in delivery method. Regarding this problem, an innovation by using an online learning application such as mobile applications is a must. There are many mobile applications provided in the Google Playstore; however, the function is either limited to one function for each mobile application or too complicated for diploma students. This paper presents the block-based programming language used in App Inventor to make the creation of mobile apps for basic electrical concepts for electrical engineering students in Politeknik namely My ReSist. This app is used to convert the resistance color codes to resistance values and calculate the total resistance in the circuit as well as to do Star-Delta transformations. Results showed that this mobile application is useful for students to solve basic electrical concept including total resistance in series and parallel circuit. It is proved that this app is user-friendly and attractive.
\end{abstract}

\section{Introduction}

Electrical Technology is one of the main courses for Diploma in Electrical Engineering students in Politeknik Malaysia. This subject requires students to know, understand and apply the basic concept of direct current in electrical circuits by solving circuit problems. It has always been delivered in the conventional, teacher-centred learning (TCL) method. However, the Covid-19 pandemic has changed the landscape in education terrene, including in the Polytechnic. Thus, a modification in teaching and learning is a must. To cater to this issue, distance-learning or online learning becoming the essential method to replace the conventional teaching and learning method for the time being.

Although online learning has many disadvantages such as distraction, complicated technology, difficulty to focus with instructors, yet the list of advantages surpassed the list of disadvantages like study from anywhere, anytime, no commuting, flexibility to choose, saving time, and earn while learning [1], [2]. Online learning applications are proven to be one of the successful methods to boost students' motivation in learning [3], [4]. Many mobile applications are developed for language [3], [5], medical [6], attendance management [7], computer science education [8], Islamic education [9], and many more.

For instance, Zakaria and Nawi [9] listed five (5) main phases in developing a mobile application, that is: (1) need analysis; (2) design; (3) development; (4) implementation; and (5) evaluation. Technically, to develop a mobile application, one must know text programming, but not all have the basic knowledge of it. Based on this situation, many programming aids like Arduino and Raspberry Pi are invented for non-programming users [10]. Recently, block-based programming using App Inventor is utilised in the development of basic electrical concepts. Block-based programming is different from text programming as it is used a puzzle-piece metaphor to provide visual cues to the user as to how and where commands might be used [8]. Furthermore, block-based programming also eases students to divert any syntax regarding text programming. Meanwhile, it promotes self-learning for the students to explore more about block-based programming itself [11]. 
There are many applications developed for basic electrical circuits, for example, series and parallel resistors by Peter Ho/Playstore, simple circuit builder by David R White/Playstore, ElectroCalc lite by SolarElectroClac/Playstore, electronics calculator by Saulawa/Playstore, resistor colour code calculator by Jedemm Technologies/Playstore, resistor code calculator by Vivid Planet Software/Playstore, and many more. Most mobile apps have a single function, such as determining the value of the resistor based on colour code or determining the resistance value in the circuit only. Some apps are too complicated such as the electronics calculator by Saulawa that can calculate resistance value up to seven (7) resistors connected in series. However, it does not show the arrangement of the resistors in that circuit.

To counter this problem, a mobile app, consists of conversion colour code and resistor band, calculation of resistance value for series and parallel circuit as well as Star-Delta and Delta-Star transformation is developed. Its purpose is to aid students in basic electrical concepts. This supplementary method facilitates students to learn resistor values, calculations of resistance in series and parallel circuits, and Star-Delta transformation in an attractive approach. This block-based mobile app is used to encourage students to learn independently (student-centred learning, SCL) whilst strengthening their understanding. Hopefully, this app could change students' perception of basic electrical concepts and thus improve their comprehension in the Electrical Technology course

\section{Research Method}

\subsection{Programming with App Inventor}

The developed prototype of the mobile app for basic electrical concepts is named My ReSist. Fig. 1 shows the development of My ReSist from start until it was published and ready to be downloaded in the Google Play store. The app is developed using block-based programming MIT App Inventor. My ReSist can be downloaded for free using the link stated: https://play.google.com/store/apps/details?id=appinventor.ai.halizahjmsk.resistor1 or by using QR code as shown in Fig.1 (b).

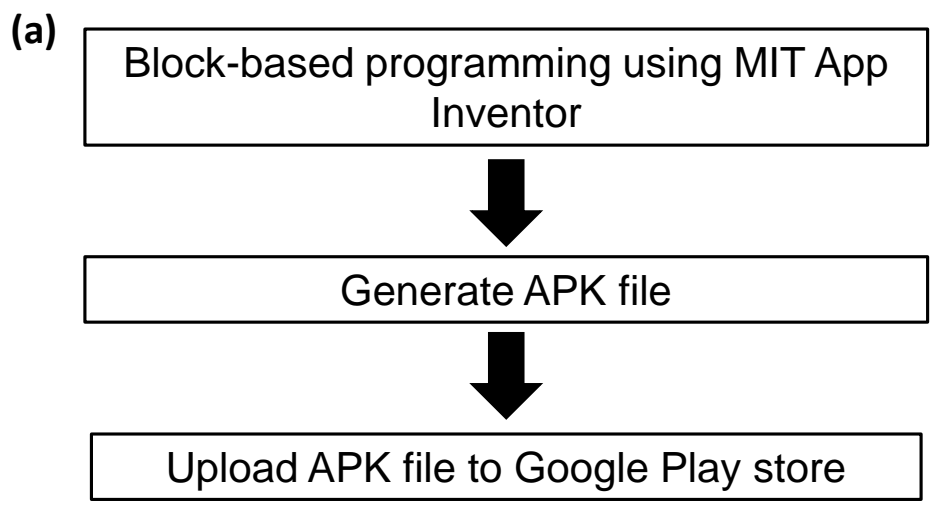

(b)

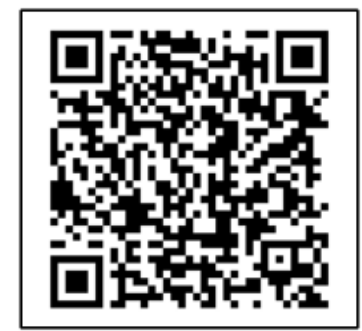

Fig. 1 - (a) Methodology of the My ReSist; (b) is the QR code

\subsection{The MIT App Inventor}

The MIT App Inventor is divided into two (2) interfaces: (1) designer interface, and (2) block interface. The designer interface shows the image displayed on the mobile phone, while the designer interface shows block-based programming. Fig. 2 shows the designer interface. The designer interface shows the display on the mobile phone. 
(a)

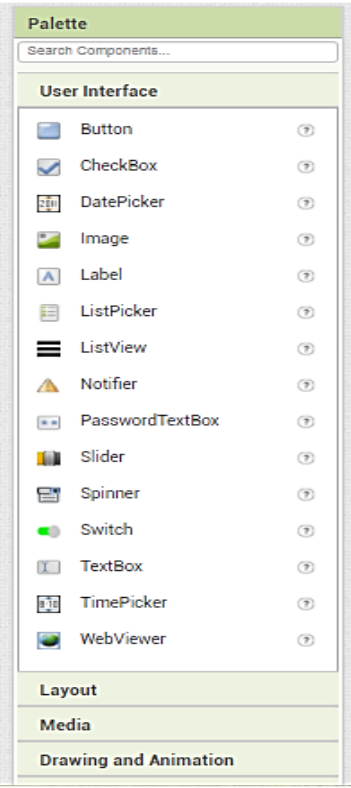

(b)

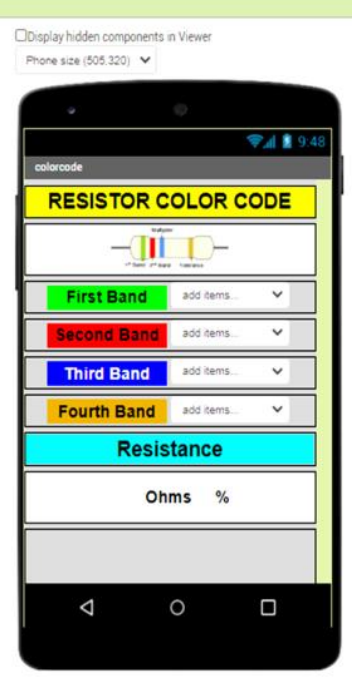

(c)

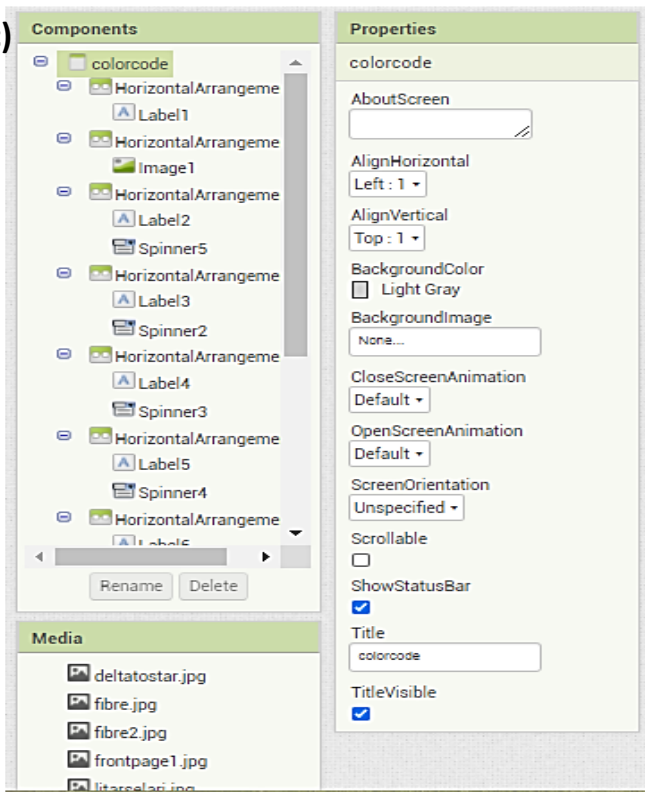

Fig. 2 - The designer interfaces: (a) the pallete; (b) viewer display; (c) components and properties settings

Then, the second part in the MIT is the block interface. The block interface is as shown in Fig.3. The figure shows that each block represents a different function according to its colours. For example, for control block is in brown, while the text block is in fuchsia colour.
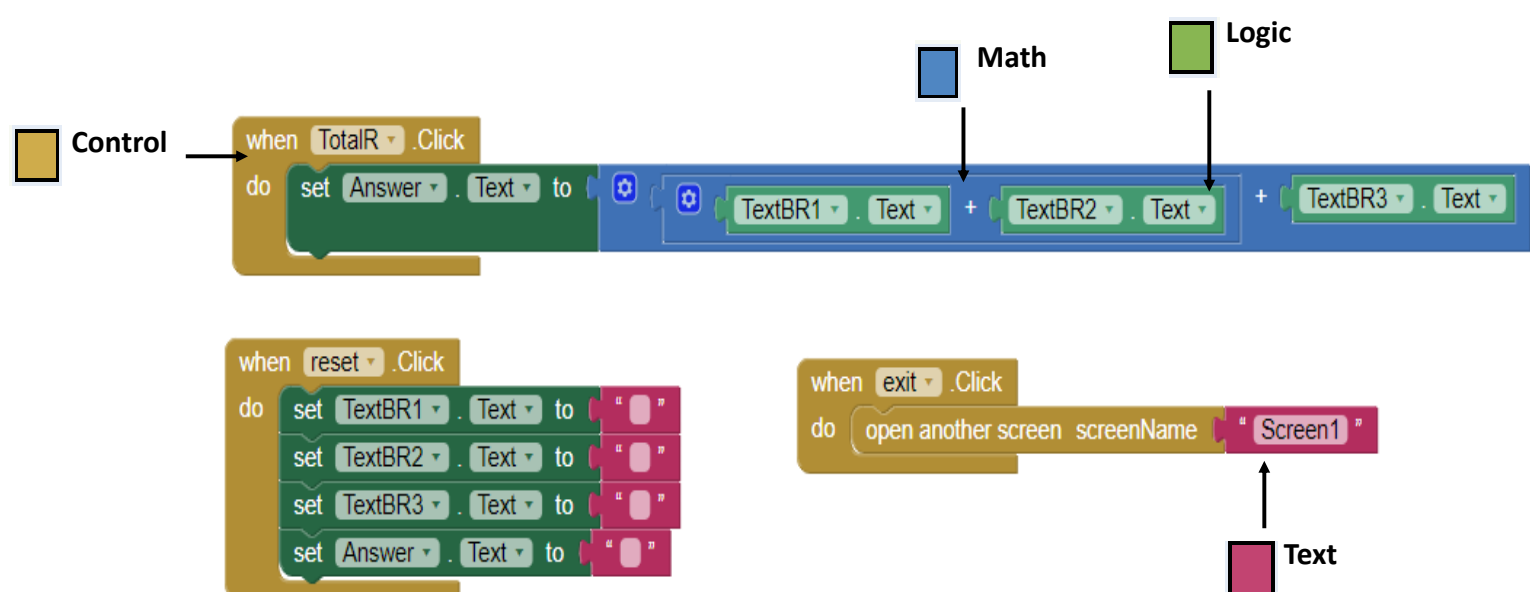

Fig. 3 - The block-interface

\subsection{Participants}

My Resist prototype was tested by eighty-five (85) diploma students in semester one (1) and semester two (2) in Diploma in Electrical Engineering at Politeknik Mersing. The participants answered the questionnaires for the feedback of the My ReSist mobile app after they tested the app. The responses were collected using Google Form. The Likert scale of agreement level has been used in the questionnaires, where: $1.00-1.49$ is for strongly disagree; $1.50-2.49$ is for Disagree; 2.50 - 3.49 is for Neutral; 3.50 - 4.49 is for Agree; and 4.50 - 5.00 is for Strongly Agree. My ReSist was then analyzed statistically to obtain the mean value for its usefulness in assisting resistance calculations. The analysis of the feedback is discussed in Results sub-section 3.3.

\section{Results and Discussion}

This section will discuss My ReSist interface. The interface is divided into two parts. The first part is the main interface, and the second part is the sub-interfaces. 


\subsection{The Main Interface of My ReSist}

My ReSist is divided into the main interface and six (6) sub-interfaces. The main interface has buttons to select menus for sub-interfaces. The six (6) sub-interfaces are named based on their function: (1) colour code to resistance is used to convert the colour chosen by the user to the value of the resistance; (2) resistance to colour code is used to convert the value of resistance to the colour of the resistance; (3) total resistance in a series circuit is used to calculate total resistance values in a series circuit; (4) total resistance in a parallel circuit is used to calculate total resistance values in a parallel circuit; (5) Star to Delta Transformation; and (6) Delta to Star Transformation are used to calculate total resistance in Star - Delta and Delta - Star respectively. Fig. 4 shows the main interface and the sub-interfaces of My ReSist.

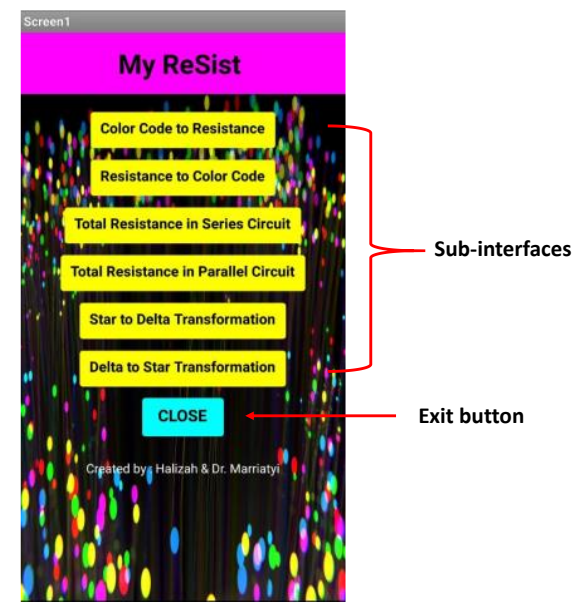

Fig. 4 - Main interface

\subsection{Sub-Interfaces of My ReSist}

Initially, the sub-interfaces are divided into three main functions, which are conversion of resistance colour code and resistance value (Fig.5), the total resistance in series and parallel circuits (Fig.6), and Star-Delta transformation (Fig.7). Fig. 5 (a) shows the sub-interfaces to convert resistor colour code to the value of resistance. Firstly, the user chooses the colour code from the first to the fourth band from the drop-down menu. The fourth band shows the colour of the resistor tolerance. The resistance value will be display in the box provided. While Fig. 5 (b) shows the conversion from resistance value to resistor colour code. Here, the user needs to choose the value of the resistance for the first band and second band from value one (1) to nine (9), the multiplier for the third band, and the tolerance value for the fourth band (either $\pm 5 \%$ or $\pm 10 \%$ ) from the drop-down menu. At the bottom of the interfaces, the colour of the resistor will be shown, in the boxes provided for each band.

(a)

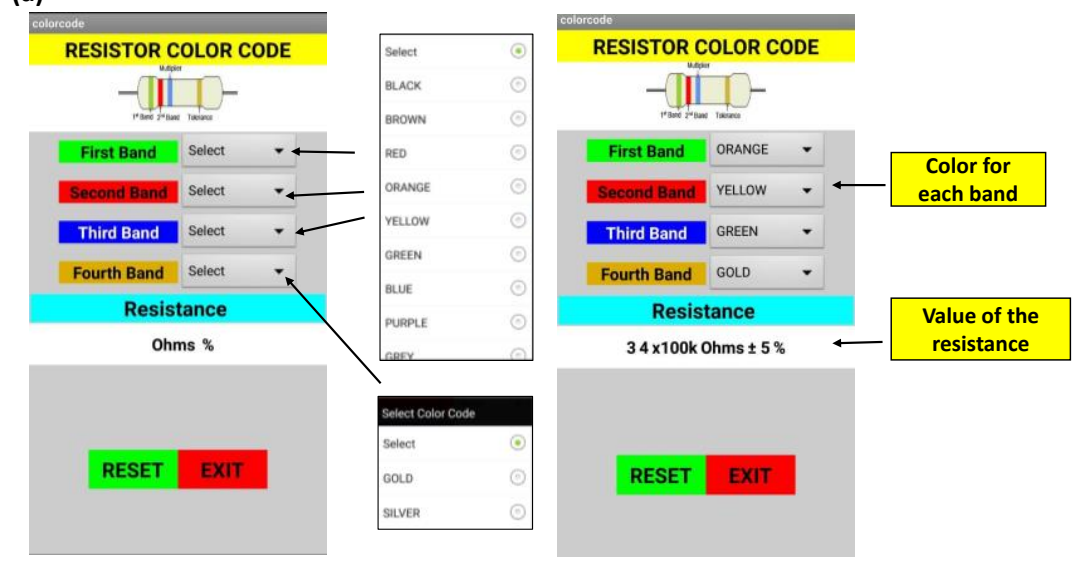




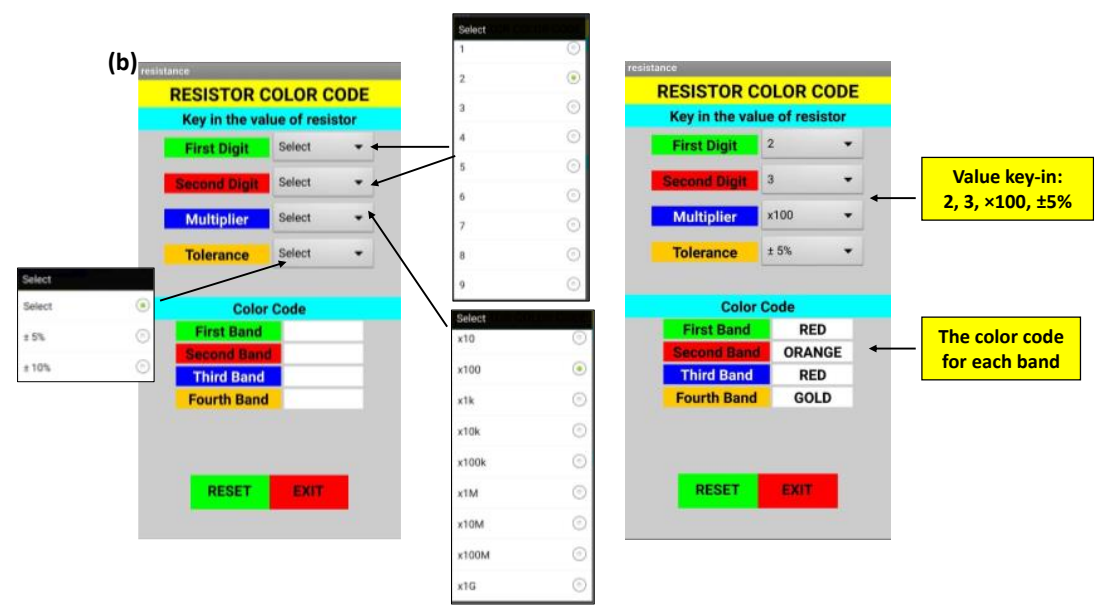

Fig. 5 - The sub-interface resistance color code

The second function of the MyReSist app is to calculate total resistance from series and parallel circuits. The series circuit contains three (3) resistors, while for parallel circuit contains two (2) resistors. Here, the user needs to key in the value for R1, R2, and R3 for the series circuit (Fig.6 (a)) and R1 and R2 for the parallel circuit (Fig. 6 (b)). The total resistance value will be displayed automatically in the box at the bottom of each interface. The example of how to key in the value of the resistors are shown in Fig. 6.
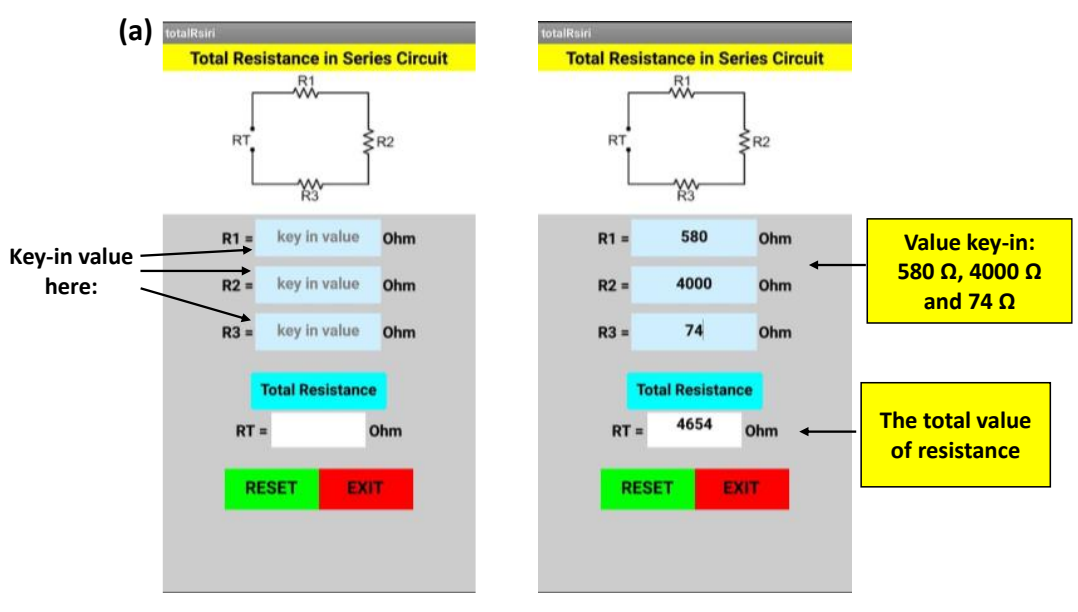

(b)
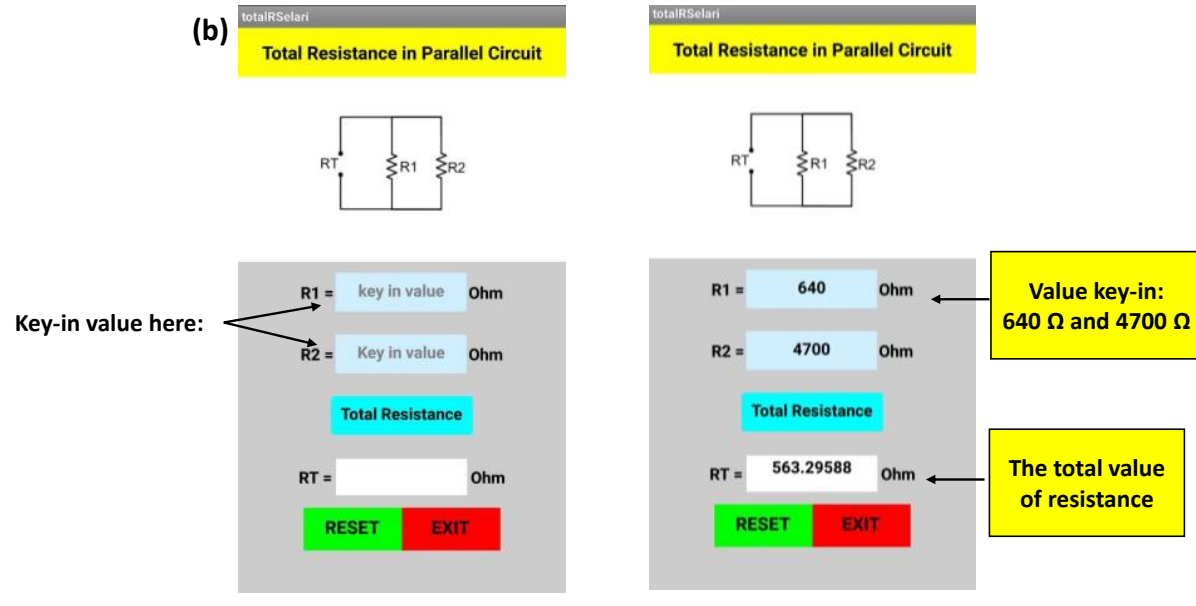

Fig. 6 - The sub-interface total resistance for: (a) series circuit; (b) parallel circuit 
The final function of MyReSist is to Star-Delta transformation. The Star-Delta transformation is divided into two (2), i.e., Star to Delta transformation (Fig. 7 (a)) and Delta to Star transformation (Fig. 7 (b)). Similarly, the user needs to key in the resistor values R1, R2, and R3 for Star to Delta transformation and Ra, Rb, and Rc for Delta to Star transformation. Then, the resistor value will automatically be converted and displayed in the box provided. This function facilitates the user to get the answer with ease. The reset button is also provided in each sub-interfaces to expedite the user to change the intended resistor values and the exit button if the user intends to end the session and return to the main interface.

(a)

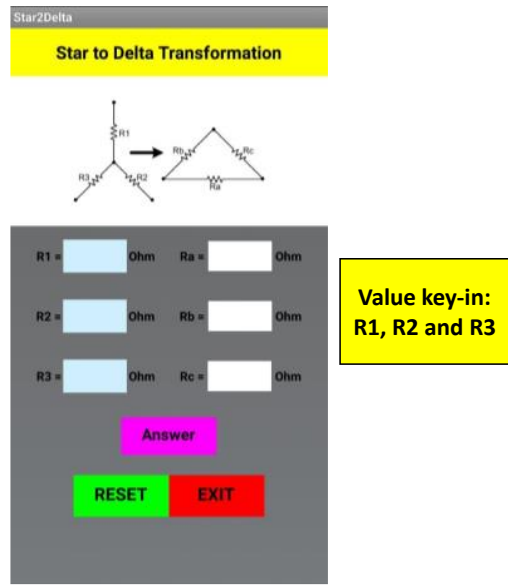

(b)

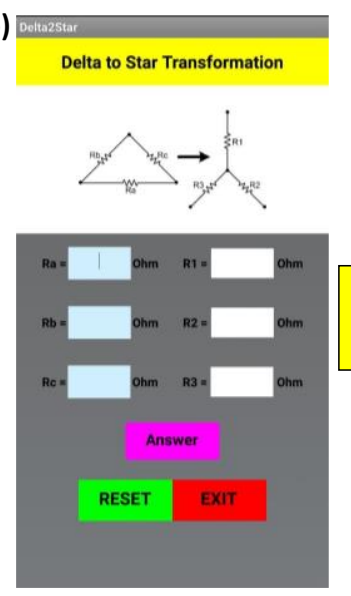

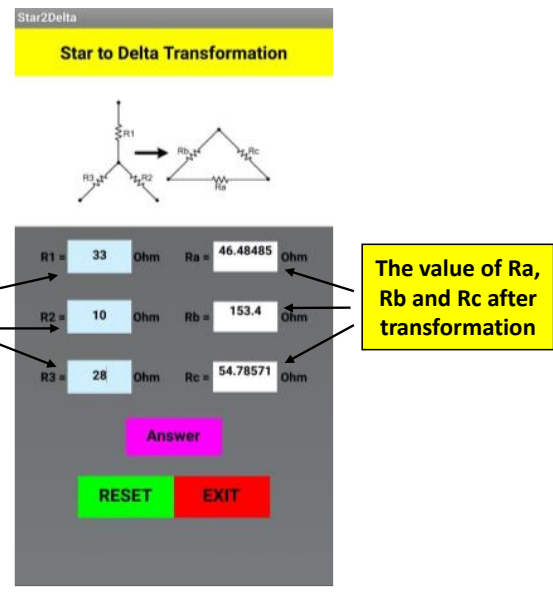
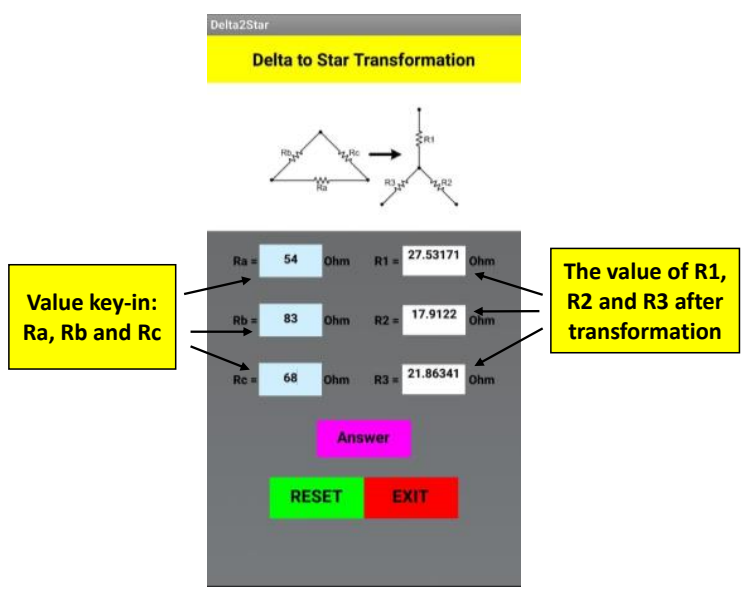

Fig. 7 - Sub-interface for resistance in: (a) Star to Delta transformation; (b) Delta to Star transformation

\subsection{Feedback from My ReSist Users}

The feedback of the My ReSist prototype is as shown in Table 1. From Table 1, the mean values above 4.50 for the functionality of My Resist showed strong agreement for Item 2, 3, and 4. While for item 1, it shows mean values of 4.48 on the response of My ReSist functionality. The feedback for the design of My ReSist shows the mean values above 4.50 only for item six (6), while item five (5), seven (7), and eight (8) show the mean values above 4.30, which agrees with the design of My ReSist. These results can that My Resist helps them calculate the total resistance based on colour, hence aids in calculating the total resistance in series, parallel, and Star-Delta circuits.

Besides that, the feedbacks also gathered other information like this app cannot be utilised by iPhone users and it needs more improvement in designs and colours. There are also some recommendations for the app, such as to include more functions, theories, and other electronic components such as capacitors. 
Table 1 - The feedback of My ReSist users

\begin{tabular}{llllllll}
\hline \multicolumn{1}{c}{ Level of agreement } & 1 & 2 & 3 & 4 & 5 & \multirow{2}{*}{ Mean } \\
\hline & \multicolumn{1}{c}{ Questions } & & & & \\
\hline
\end{tabular}

\section{Conclusion}

This study has proposed a supplementary method of learning basic electrical concepts using an app called My ReSist. This app is free and is ready to be downloaded from the Google Play Store or using a QR code and it can be used seamlessly anywhere and anytime. This app assists students in learning to convert the colour code of resistance to its value and vice-versa, calculate the total resistance of series and parallel circuits and ease the conversion of resistance from Star-Delta transformation. No calculator is needed as the app does the work. Meanwhile, the feedback from users agreed that this app assists in understanding basic electrical concepts by using this app as a reference in checking the answer from the calculated exercises given by lecturers. Further suggestions are to add theory notes, impedance, and other electrical theorems calculations.

\section{Acknowledgment}

The authors would like to thank the Department of Electrical Engineering of Politeknik Mersing for their support and cooperation, the students and other individuals who were directly or indirectly involved in this project.

\section{References}

[1] M. Sadeghi, "A Shift from Classroom to Distance Learning: Advantages and Limittations," Int. J. Res. English Educ., vol. 4, no. 1, pp. 80-88, 2019

[2] P. S. Muljana and T. Luo, "Factors contributing to student retention in online learning and recommended strategies for improvement: A systematic literature review," J. Inf. Technol. Educ. Res., vol. 18, pp. 19-57, 2019

[3] M. M. Elaish, N. A. Ghani, L. Shuib, and A. Al-Haiqi, "Development of a Mobile Game Application to Boost Students' Motivation in Learning English Vocabulary," IEEE Access, vol. 7, pp. 13326-13337, 2019

[4] C. Chang, C. K. Chang, and J. L. Shih, "Motivational strategies in a mobile inquiry-based language learning setting," System, vol. 59, pp. 100-115, 2016

[5] R. Godwin-Jones, "Emerging technologies: Mobile apps for language learning," Lang. Learn. Technol., vol. 15, no. 2, pp. 2-11, 2011

[6] S. Thakre and S. Thakre, "Perception of medical students for utility of mobile technology use in medical education," Int. J. Med. Public Heal., vol. 5, no. 4, pp. 305-311, 2015

[7] J. Iio, "Attendance Management System Using a Mobile Device and a Web Application," NBiS 2016 - 19th Int. 
Conf. Network-Based Inf. Syst., no. September 2016, pp. 510-515, 2016

[8] D. Weintrop, "Education block-based programming in computer science education," Commun. ACM, vol. 62, no. 8, pp. 22-25, 2019

[9] G. A. N. Zakaria and A. Nawi, "Design and development of a PBL mobile application in Islamic education: A conceptual framework," Int. J. Inf. Educ. Technol., vol. 10, no. 1, pp. 26-30, 2020

[10] I. Ruiz-Rube, J. M. Mota, T. Person, J. M. R. Corral, and J. M. Dodero, "Block-based development of mobile learning experiences for the internet of things," Sensors (Switzerland), vol. 19, no. 24, 2019

[11] T. W. Price and T. Barnes, "Position paper: Block-based programming should offer intelligent support for learners," Proc. - 2017 IEEE Blocks Beyond Work. B B 2017, vol. 2017-Novem, pp. 65-68, 2017 